\title{
Results of interventional bronchoscopy in the management of postoperative tracheobronchial stenosis
}

\author{
Byeong-Ho Jeong, MD, ${ }^{\mathrm{a}}$ Sang-Won Um, MD, PhD, ${ }^{\mathrm{a}}$ Gee Young Suh, MD, PhD, ${ }^{\mathrm{a}}$ Man Pyo Chung, MD, \\ $\mathrm{PhD},{ }^{\mathrm{a}}{ }^{\mathrm{O}}$ Jung Kwon, $\mathrm{MD}, \mathrm{PhD},{ }^{\mathrm{a}}$ Hojoong Kim, MD, PhD, ${ }^{\mathrm{a}}$ and Jhingook Kim, MD, $\mathrm{PhD}^{\mathrm{b}}$
}

Objectives: To investigate the role of bronchoscopic intervention in the management of postoperative tracheobronchial stenosis, a retrospective study was performed at a tertiary referral hospital.

Methods: Thirty patients who underwent 106 bronchoscopic interventions between January 2000 and July 2010, including ballooning, bouginage, Nd:YAG laser resection, and stent insertion, were included and followed up for a median of 34 months.

\begin{abstract}
Results: Silicone stents were required in 19 of 30 patients $(63 \%)$ to maintain airway patency. Bronchoscopic intervention provided improvement of dyspnea in $97 \%$ of the patients. After airway stabilization, the stents were removed successfully in 7 of 19 patients $(37 \%)$ a median of 7 months after insertion. In 3 patients $(10 \%)$, the intervention failed to widen the airway. There were no procedure-related deaths or cases of pneumonia, although additional interventions were needed in 9 patients (30\%) within 30 days. Stent-related late complications $(70 \%)$, such as restenosis $(43 \%)$, overgrowth of granulation tissue $(33 \%)$, stent migration $(32 \%)$, mucostasis $(30 \%)$, and malacia after stent removal $(16 \%)$, were controllable at follow-up bronchoscopy.
\end{abstract}

Conclusions: Bronchoscopic intervention could be a useful treatment modality for patients with postoperative tracheobronchial stenosis when surgery is not feasible. (J Thorac Cardiovasc Surg 2012;144:217-22)

Postoperative tracheobronchial stenosis (POTS) may result from disruption of the vascular supply, tension of the anastomotic site, or infection. ${ }^{1,2}$ Despite better understanding of bronchial healing and the vascular supply of the tracheobronchial tree, POTS still occurs in $1.8 \%$ to $8.7 \%$ of patients and remains a serious complication of tracheobronchial resection with or without end-to-end anastomosis. $^{3-5}$

The treatment of choice for benign tracheobronchial stenosis is segmental resection of the stenosis site with end-toend anastomosis. ${ }^{6}$ Regardless of whether POTS occurs after airway resection with or without lung parenchymal resection, however, most affected patients cannot undergo surgical correction because of low remaining lung function, poor general condition, and technical difficulties. In these situations, bronchoscopic interventions, such as airway stenting, ballooning, laser, and mechanical bouginage, may be reasonable therapeutic modalities, along with the development of intervention techniques. ${ }^{7}$ However, there are few

\footnotetext{
From the Division of Pulmonary and Critical Care Medicine, ${ }^{a}$ Department of Medicine, and the Department of Thoracic Surgery, ${ }^{\mathrm{b}}$ Samsung Medical Center, Sungkyunkwan University School of Medicine, Seoul, Korea.

Disclosures: Authors have nothing to disclose with regard to commercial support.

Received for publication Feb 18, 2011; revisions received March 9, 2012; accepted for publication March 30, 2012; available ahead of print May 7, 2012.

Address for reprints: Hojoong Kim, MD, PhD, Division of Pulmonary and Critical Care Medicine, Department of Medicine, Samsung Medical Center, Sungkyunkwan University School of Medicine, 50 Irwon-dong, Gangnam-gu, Seoul 135-

710, Korea (E-mail: hjk3425@skku.edu).

$0022-5223 / \$ 36.00$

Copyright (C) 2012 by The American Association for Thoracic Surgery

doi:10.1016/j.jtcvs.2012.03.077
}

reports on the efficacy or safety of bronchoscopic interventions for POTS. This study therefore investigated the efficacy and safety of interventional bronchoscopy for POTS.

\section{MATERIALS AND METHODS \\ Study Population}

The study was approved by the institutional review board of Samsung Medical Center, a 1950-bed tertiary care general hospital in Seoul, Korea. A retrospective review of medical records was performed for all patients between January 2000 and July 2010 for whom all the following conditions were met: (1) the patients underwent surgery; (2) airway stenosis developed postoperatively, as confirmed by chest radiography, computed tomography, or bronchoscopy, (3) respiratory symptoms related to POTS, such as dyspnea, cough, or chest pain, were present; and (4) bronchoscopic interventions were performed to widen the stenotic airway. In total, 35 patients met these inclusion criteria. Patients were excluded if they had less than 2 months of follow-up or postprocedural information because of emergency referral from another hospital. Ultimately, 30 patients were included.

The following data were investigated and analyzed: demographic characteristics, underlying diseases, reason for surgery, type of surgery, pulmonary function tests at baseline and after the procedure, interventional bronchoscopic findings, methods of bronchoscopic intervention, clinical outcome, and procedure-related complications.

\section{Airway Intervention Techniques}

The indications for bronchoscopic intervention in our institution were as follows: (1) more than 50\% stenosis in the trachea or complete or almost complete atelectasis of 1 lung and (2) symptomatic dyspnea (greater than American Thoracic Society grade 3), cough, or chest pain.

Airway anatomy and function were evaluated by chest radiography, computed tomography, flexible bronchoscopy, and, if possible, spirometry. Airway intervention was performed according to the standard techniques of Colt and Dumon ${ }^{8}$ and of Kim. ${ }^{9}$ After induction of general anesthesia, patients were intubated with a rigid bronchoscopic tube (Hopkins; Karl Storz GmbH \& Co, Tuttlingen, Germany). A flexible bronchoscope (EVIS BF 


\section{Abbreviations and Acronyms}

$\mathrm{FEV}_{1}=$ forced expiratory volume in 1 second

POTS $=$ postoperative tracheobronchial stenosis

1T240; Olympus Corporation, Tokyo, Japan) was then introduced through the rigid bronchoscope, and the airway narrowing was evaluated.

For ballooning, a 10- or 12-mm controlled radial expansion balloon (Boston Scientific Corporation, Natick, Mass) was inflated 2 or 3 times to 3 atmospheres for 20 seconds. When localized dense fibrosis was observed, an Nd:YAG laser (LaserSonics, Milpitas, Calif) was used to cut the fibrotic bands with a G56D noncontact fiber (LaserSonics). Fibrotic stenoses were also gently dilated mechanically with a rigid bronchoscope (bouginage), followed immediately by stent insertion.

Silicone stenting was indicated when (1) malacia of more than $180^{\circ}$ of the angle of the dilated lumen was observed, (2) the longitudinal stenotic segment was longer than $2 \mathrm{~cm}$, or (3) there was a third recurrence of airway narrowing after ballooning. Airway stents were implanted according to the standard technique described by Dumon. ${ }^{10}$ A stent of the appropriate size was folded longitudinally, introduced into a stent pusher, and properly repositioned with alligator forceps.

After airway intervention, symptomatic relief was determined by a dyspnea scale survey administered on postprocedure day 1 . Patients were usually discharged from the hospital 1 to 3 days after the procedure and were followed up 1, 3, 6, 9, and 12 months after the procedure with chest radiography and spirometry. Bronchoscopy and chest computed tomography were performed when needed to reassess the stent position and effectiveness. Stent removal was planned once the patients had been in stable condition for longer than 6 months.

\section{Stents}

In this study, the types of stents used were the Natural stent (M1S Co, Seoul, Korea), the Dumon stent (BryanCorp, Woburn, Mass), the Y-stent (BryanCorp), and the Montgomery T-tube (Koken, Tokyo, Japan). No metal stents were used. ${ }^{11}$

The Natural stent is a silicone stent developed at the Samsung Medical Center in 2002. Studies in a canine model of tracheal stenosis and clinical experience in patients with benign tracheobronchial stenosis have shown that the Natural stent is as effective and safe as the Dumon stent. ${ }^{12,13}$ Either the Dumon or Natural stent was selected according to the availability and bronchoscopist's preference.

The Y-stent is a Y-shaped silicone stent designed for stenoses of the trachea, both bronchi, and the carina. The Montgomery T-tube was used in patients with upper tracheal stenosis, usually after a postoperative tracheostomy. ${ }^{14}$

\section{Statistical Analysis}

Continuous variables are expressed as the median and range, and categoric variables are expressed as numbers with percentages. To assess the effectiveness of bronchoscopic interventions according to objective data, the forced expiratory volume in 1 second $\left(\mathrm{FEV}_{1}\right)$ values before and after bronchoscopic interventions were compared with the Wilcoxon signedrank test. The survival curve of patients was calculated with the KaplanMeier method. All statistical tests were 2 -tailed, and $P$ values $<.05$ were considered to indicate statistical significance.

\section{RESULTS}

\section{Baseline Patient Characteristics}

The baseline characteristics of the study populations are summarized in Table 1. Malignant neoplasms $(50 \%)$ were
TABLE 1. Baseline patient characteristics

\begin{tabular}{lc}
\hline Subjects & 30 \\
Male (no.) & $16(53 \%)$ \\
Age (y, median and range) & $59(9-74)$ \\
Reason for operation (no.) & \\
Malignant neoplasm (no.) & $15(50 \%)$ \\
$\quad$ Malignant neoplasm of bronchus or lung & $12(40 \%)$ \\
$\quad$ Malignant neoplasm of trachea & $3(10 \%)$ \\
Postintubation tracheal stenosis & $6(20 \%)$ \\
Posttuberculosis tracheobronchial stenosis & $3(10 \%)$ \\
Trauma (traffic accident) & $2(7 \%)$ \\
Chemical intoxication & $2(7 \%)$ \\
Other (benign mass, ectopic thyroid mass) & $2(7 \%)$ \\
Type of operation (no.) & \\
Tracheal resection and anastomosis & $10(33 \%)$ \\
Lobectomy & $8(27 \%)$ \\
Sleeve right upper lobectomy & $6(20 \%)$ \\
Carinal resection and reconstruction & $2(7 \%)$ \\
Other* & $4(13 \%)$ \\
Interval from surgery to interventional & $54(4-481)$ \\
bronchoscopy (d, median and range) & \\
Baseline pulmonary function test results (n $=13)$ & \\
FEV ${ }_{1}$ percentage of predicted value & $55 \%(25 \%-84 \%)$ \\
(median and range) & \\
FVC percentage of predicted value & $63 \%(43 \%-79 \%)$ \\
(median and range) & \\
FEV ${ }_{1} /$ FVC (median and range) & $65(33-87)$ \\
\hline FEV Forced &
\end{tabular}

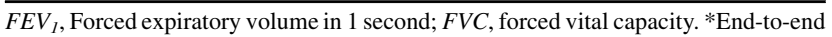
anastomosis of left main bronchus; carinal resection and reconstruction with right upper lobectomy; resection of distal trachea, right main bronchus to distal bronchus intermedius, and right upper lobe bronchus, reconstruction of secondary carina, end-to end-anastomosis between distal trachea and reconstructed bronchus; and left lower lobectomy and end-to-end anastomosis of left main bronchus to left upper lobar bronchus.

the most common reason for surgery, and the most common operation was tracheal resection and anastomosis $(33 \%)$. The interval from surgery to interventional bronchoscopy was a median of 54 days (range, 4-481 days). Before interventional bronchoscopy, baseline pulmonary function tests were conducted in 13 of 30 patients $(43 \%)$. Their percentage of predicted $\mathrm{FEV}_{1}$ was $55 \%$ (range, $25 \%-84 \%$ ).

\section{Bronchoscopic Findings and Interventions}

The bronchoscopic findings and interventions are summarized in Table 2. The types of stenosis could be classified as fibrous stricture, overgrowth of granulation tissue, and malacia.

The most common method of airway intervention was stent insertion, which was performed in 19 of 30 patients $(63 \%)$. There were a total of 50 stents placed (33 Natural stents, 13 Y-stents, 3 Dumon stents, and 1 Montgomery T-tube), and a median of 2 (range, 1-15) stents per patient were used. The interventions usually involved a combination of modalities, however, such as ballooning, bouginage (mechanical dilatation with rigid tubes), and Nd:YAG laser cauterization. In total, 106 interventional bronchoscopic procedures were performed in the 30 patients. A median 
TABLE 2. Bronchoscopic findings and interventions $(n=30)$

\begin{tabular}{lrr}
\hline & No. & $\%$ \\
\hline Stenosis site & 10 & \\
Trachea & 8 & $33 \%$ \\
Bronchus intermedius & 7 & $27 \%$ \\
One main bronchus & 2 & $23 \%$ \\
Both main bronchi & 2 & $7 \%$ \\
Carina & 1 & $7 \%$ \\
Left lower lobar bronchus & & $3 \%$ \\
Stenosis type & 16 & \\
Overgrowth of granulation tissue & 12 & $53 \%$ \\
Fibrous stricture & 2 & $40 \%$ \\
Malacia & & $7 \%$ \\
Method of airway dilatation (overlapping data) & \\
Stent insertion & 19 & $63 \%$ \\
Bouginage & 18 & $60 \%$ \\
Ballooning & 17 & $57 \%$ \\
Nd:YAG laser & 11 & $37 \%$ \\
\hline
\end{tabular}

of 2.5 bronchoscopic interventions (range, 1-23 interventions) were performed per patient during a median followup period of 34 months. Among the 30 patients, 17 patients underwent a single intervention successfully. Thirteen patients underwent a second intervention an average of 79.5 days after the first intervention. Three patients underwent intervention more than 5 times $(8,10$, and 23 times). The patient who required 23 interventions was followed up for 103 months after the carinal resection and reconstruction because of adenoid cystic carcinoma. Another 2 patients had undergone extensive resection and anastomosis for posttuberculosis tracheobronchial stenosis.

\section{Outcomes and Complications}

The overall clinical outcomes are summarized in Table 3 and Figure 1. Improvement of dyspnea was achieved 1 day after the first intervention in 29 of 30 patients (97\%). Because many patients were unable to complete spirometry because of their severe dyspnea and poor general condition, 9 patients underwent pulmonary function testing both before and after the procedures. In these patients, the percentage of predicted $\mathrm{FEV}_{1}$ was improved significantly, by $22 \%$ $(-31 \%$ to $200 \%)$ relative to baseline values.

Overall $19(63 \%)$ patients were treated with stents; stents were inserted during the initial bronchoscopic intervention in 14 patients and during the follow-up interventions in 5 patients. In 7 of 19 patients, the stent could be removed. The median duration of stent placement in these patients was 7 months (1-22 months), and the duration of followup after stent removal was 57 months (13-74 months). In 1 of these 7 patients, we failed to widen the stricture of the right bronchus intermedius that occurred after a sleeve right upper lobectomy performed to treat lung cancer.

In the remaining 12 patients, the stent was not removed. In 8 patients, there were extensive losses of cartilage and
TABLE 3. Outcomes and complications of bronchoscopic interventions in 30 patients with postoperative tracheobronchial stenosis

\begin{tabular}{|c|c|}
\hline Improvement of dyspnea (no.) & $29(97 \%)$ \\
\hline Successful single intervention (no.) & $17(57 \%)$ \\
\hline $\begin{array}{l}\text { Average time before second intervention } \\
\qquad(\mathrm{d}, \mathrm{n}=13)\end{array}$ & 79.5 \\
\hline Stent insertion (no.) & $19(63 \%)$ \\
\hline Successful stent removal (no.) & 7 \\
\hline $\begin{array}{l}\text { Duration of stent placement } \\
\text { (mo, median and range) }\end{array}$ & $7(1-22)$ \\
\hline $\begin{array}{l}\text { Duration of follow-up after stent removal } \\
\text { (mo, median and range) }\end{array}$ & $57(13-74)$ \\
\hline Persistent stent placement (no.) & 12 \\
\hline $\begin{array}{l}\text { Duration of stent placement } \\
\text { (mo, median and range) }\end{array}$ & $16(2-101)$ \\
\hline \multicolumn{2}{|l|}{$\begin{array}{l}\mathrm{FEV}_{1} \text { percentage of predicted } \\
\quad(\text { median and range, } \mathrm{n}=9)\end{array}$} \\
\hline Before interventions & $51 \%(25 \%-65 \%)$ \\
\hline After interventions & $61 \%(22 \%-84 \%)$ \\
\hline Change after interventions $(\%)^{*}$ & $22 \%(-31 \%$ to $200 \%)$ \\
\hline 30-d complications (no.) & $9(30 \%)$ \\
\hline 30-d mortality & 0 \\
\hline Intervention-related pneumonia & 0 \\
\hline Need for repeated intervention within $30 \mathrm{~d}$ & $9(30 \%)$ \\
\hline Intubation within $<2 \mathrm{~d}$ & $2(7 \%)$ \\
\hline Stent migration within $30 \mathrm{~d}(\mathrm{n}=19)$ & $2(11 \%)$ \\
\hline Late complications (no, multiples counted) & $21(70 \%)$ \\
\hline Restenosis & $13(43 \%)$ \\
\hline Overgrowth of granulation tissue & $10(33 \%)$ \\
\hline Mucostasis & $9(30 \%)$ \\
\hline Stent migration $(\mathrm{n}=19)$ & $6(32 \%)$ \\
\hline Malacia after stent removal $(n=19)$ & $3(16 \%)$ \\
\hline
\end{tabular}

$F E V_{l}$, Forced expiratory volume in 1 second. ${ }^{*}$ Change calculated as follows: (baseline value - value after intervention)/baseline value $\times 100 \% ; P=.038$.

persistent malacia after endobronchial tuberculosis $(\mathrm{n}=4)$, radiation therapy $(\mathrm{n}=2)$, or chemical burn $(\mathrm{n}=2)$. The remaining 2 patients refused removal $(\mathrm{n}=2)$. The median duration of stent placement in these 12 patients was 16 months (2-101 months).

During the entire follow-up period, $11(37 \%)$ patients underwent bronchoscopic intervention without stenting. Among these patients, 1 patient underwent pneumonectomy because of massive hemoptysis and suspected restenosis because of the sequelae of pulmonary tuberculosis, unrelated to the interventional bronchoscopic procedure. In another patient, we failed to widen the stenosis of the right main bronchus that occurred after a sleeve right upper lobectomy for lung cancer.

Overall, 3 of 30 patients $(10 \%)$ in whom bronchoscopic intervention failed could not undergo any surgical correction because of low remaining lung function, poor general condition, and technical difficulties. In 2 of these 3 cases, we referred patients back to their hometown hospitals with supportive care after follow-up durations of 3.3 and 


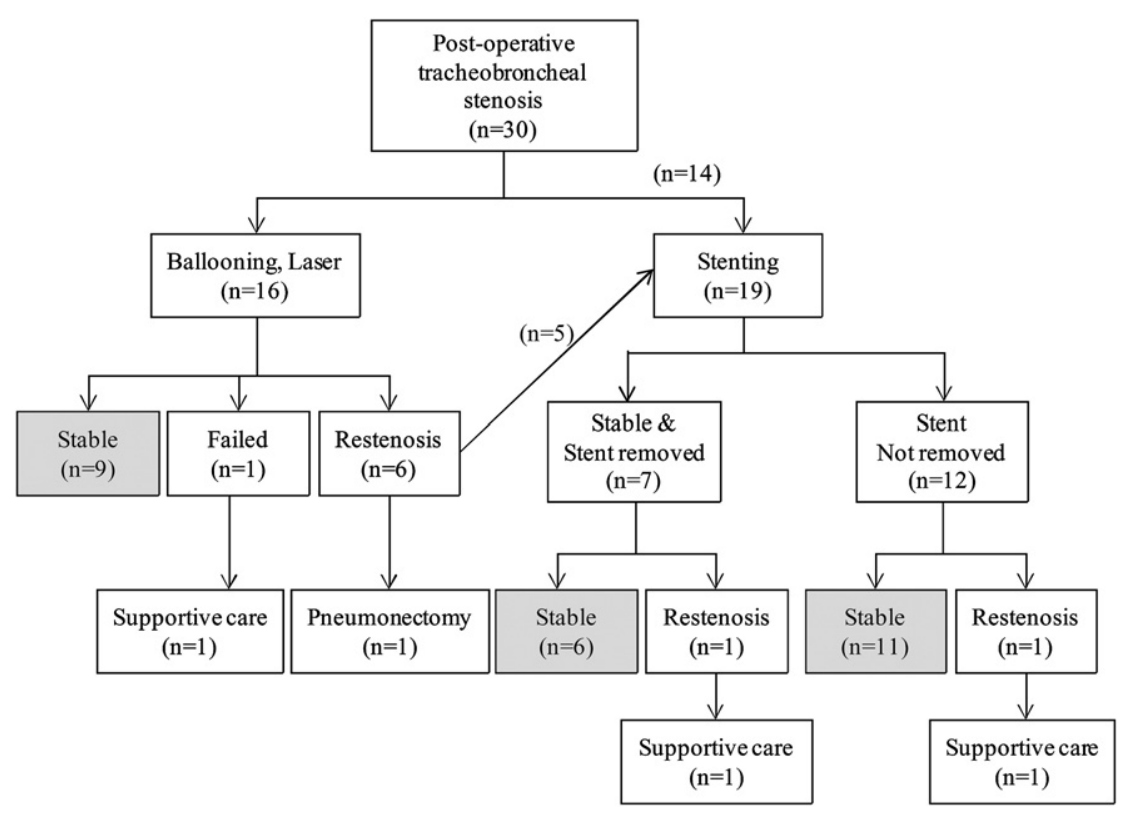

FIGURE 1. The overall clinical outcomes of interventional bronchoscopy in patients with postoperative tracheobronchial stenosis.

11.4 months from the last intervention. The other patient died of cancer progression after a follow-up duration of 18.2 months from the last intervention.

Overall complications are shown in Table 3. Minor complications, such as pain and fever, were relatively common, but there were no cases of procedure-related pneumonia or death. Within 30 days after the procedure, repeated intervention was needed in 9 patients (30\%), including endotracheal intubation within less than 2 days in 2 patients $(7 \%)$ and stent repositioning as a result of migration in 2 patients $(11 \%)$. Stent-related late complications were common $(70 \%)$. Restenosis developed in 13 patients $(43 \%)$, granulation tissue formed at the site of the procedure in 10 patients $(33 \%)$, mucostasis necessitated bronchoscopic toilet in 9 patients $(30 \%)$, stent migration occurred in 6 patients $(32 \%)$, and malacia of the trachea or bronchus after stent removal developed in 3 patients $(16 \%)$. Repeated bronchoscopic interventions were needed to treat these complications.

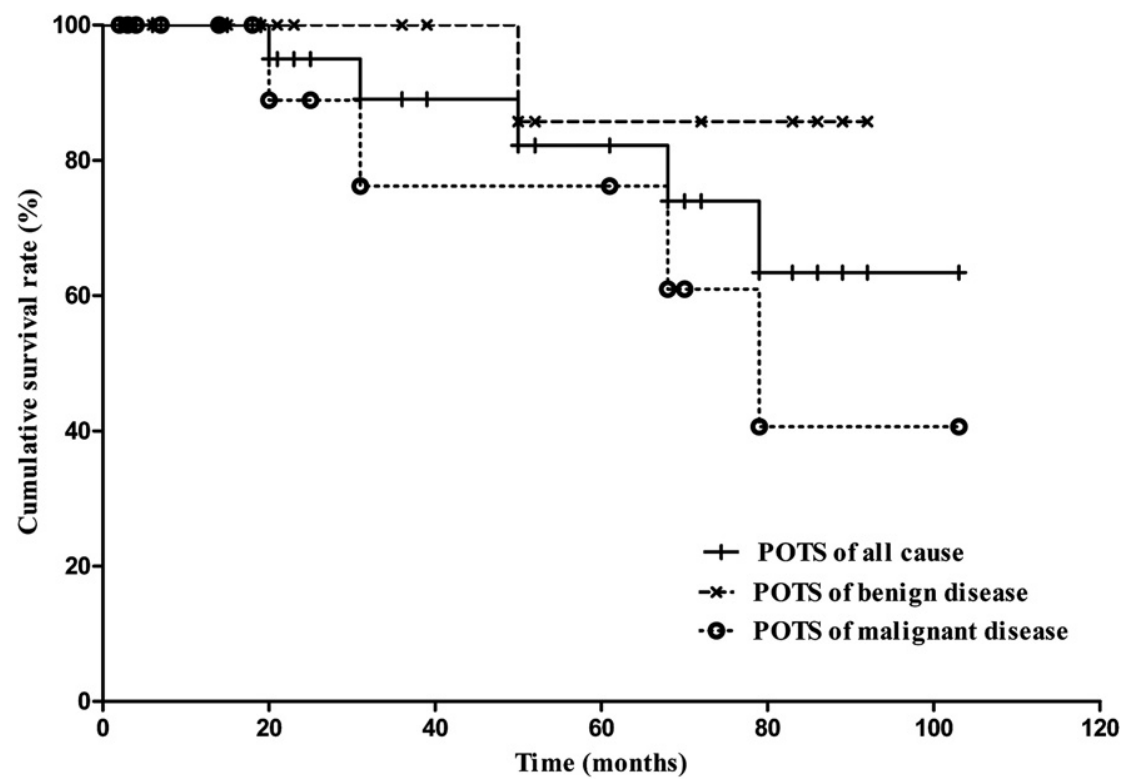

FIGURE 2. Survival curves after first bronchoscopic intervention of patients with postoperative tracheobronchial stenosis (POTS) for all causes, for benign disease, and for malignant disease. No significant difference could be seen between postoperative tracheobronchial stenosis associated with benign disease and that associated with malignant disease by log-rank test $(P=.121)$. The survivals among patients with POTS of all causes at 3 and 5 years after first intervention were $89 \%$ and $82 \%$, respectively. 


\section{Disease Course and Survival}

During follow-up, 5 patients died within a median of 50 months (20-79 months). The cause of death was not related to POTS or interventional bronchoscopy in any cases. Causes of death were cancer progression $(n=2)$, acute leukemia $(n=1), H 1 N 1$ influenza-related pneumonia $(n=1)$, and massive hemoptysis $(\mathrm{n}=1)$. The survival probabilities, as evaluated with the Kaplan-Meier method, are shown in Figure 2. The probability of being alive at 3 years after the first interventional bronchoscopy was $89 \%$; the probability at 5 years was $82 \%$.

\section{DISCUSSION}

In this study, immediate improvement of dyspnea was achieved in $97 \%$ of the patients after interventional bronchoscopy. Objectively, the percentage of predicted $\mathrm{FEV}_{1}$ also increased significantly, by $22 \%$ ( $-31 \%$ to $200 \%)$ after the intervention. These positive results are consistent with the results obtained with other causes of benign tracheobronchial stenosis. ${ }^{15-20}$ Five patients died during the follow-up period, but no deaths was associated with POTS or interventional bronchoscopy. It was very encouraging that only 3 of these 30 nonsurgical patients had failure of bronchoscopic intervention and that there were no procedure-related deaths.

Most patients (70\%) did have late complications, such as restenosis $(43 \%)$, granulation formation $(33 \%)$, mucostasis $(30 \%)$, stent migration $(32 \%)$, and malacia after stent removal $(16 \%)$. These rates are consistent with studies of patients with benign tracheobronchial stenosis other than POTS. ${ }^{13,15,16,21}$ Even with this high incidence of late complications, repeated bronchoscopic interventions could control most of the complications except in 3 cases. Patients undergoing bronchoscopic intervention do require close monitoring, because the initial procedure is often not durable and a third of patients will require repeated interventions throughout their course.

Malacia after stent removal occurred in 3 of 19 patients with stenting $(16 \%)$; this has not been reported in studies of benign tracheobronchial stenosis with other causes, such as postuberculosis and postintubation stenosis. We suggest that the malacia resulted from excessive tension after agonistic anastomosis, decreased vascularity of the bronchial wall, and continued inflammation caused by suture material, followed by broad, transmural injuries of the bronchial wall. In these 3 cases, the stents could not be removed within 7,25 , and 78 months after the malacia developed. The stent may have caused damage to the airway wall, leading to malacia, especially in patients who received a stent but did not have malacia in the first place.

Our experience included 8 patients with POTS after simple lobectomy. Seven of the 8 patients had calcified lymph nodes near the lobectomy stump before the surgery. Although there was no evidence of reactivation of tuberculosis in these patients, the cause of calcified lymph nodes is likely related, because tuberculosis was highly prevalent in South Korea 20 years ago. It might be postulated that POTS could be a result of the adjacent calcified lymph nodes and associated chronic granulomatous inflammation.

This study has several limitations. First, it was a retrospective study of a heterogeneous patient population with various interventions and outcomes; thus, the objective data to prove clinical efficacy are lacking. The reason for this lack of objective data is that the patients were critically ill at the time of intervention. Although interventions were usually performed in a critical situation, we used accepted methods and guidelines of bronchoscopic intervention. Postprocedure efficacy was therefore determined during the same hospitalization, rather than through longer term follow-up. Second, this case series was small; however, this is only the first study to evaluate the results of POTS statistically. Third, some outcomes were measured by subjective methods. For example, symptomatic relief was determined by a dyspnea scale survey. Finally, because this study was performed in a single institution in Korea, selection bias is probable. Ten of 30 patients $(33 \%)$ ) were referred from other hospitals, so it is impossible to investigate the exact total number of patients with airway complications after the surgery.

In conclusion, interventional bronchoscopy appears to be an alternative treatment modality for patients with POTS in whom surgery is not feasible. Further clinical studies should follow.

\section{References}

1. Freitag L. Airway stents. In: Strausz J, Bolliger CT, eds. Interventional pulmonology. Sheffield, UK: European Respiratory Society; 2010. p. 190-217.

2. Grillo HC, Donahue DM, Mathisen DJ, Wain JC, Wright CD. Postintubation tracheal stenosis. Treatment and results. J Thorac Cardiovasc Surg. 1995; 109:486-93.

3. Yildizeli B, Fadel E, Mussot S, Fabre D, Chataigner O, Dartevelle PG. Morbidity, mortality, and long-term survival after sleeve lobectomy for non-small cell lung cancer. Eur J Cardiothorac Surg. 2007;31:95-102.

4. Terzi A, Lonardoni A, Falezza G, Furlan G, Scanagatta P, Pasini F, et al. Sleeve lobectomy for non-small cell lung cancer and carcinoids: results in 160 cases. Eur J Cardiothorac Surg. 2002;21:888-93.

5. Kutlu CA, Goldstraw P. Tracheobronchial sleeve resection with the use of a continuous anastomosis: results of one hundred consecutive cases. J Thorac Cardiovasc Surg. 1999;117:1112-7.

6. Shin JH, Song HY, Shim TS. Management of tracheobronchial strictures. Cardiovasc Intervent Radiol. 2004;27:314-24.

7. Shitrit D, Kuchuk M, Zismanov V, Rahman NA, Amital A, Kramer MR. Bronchoscopic balloon dilatation of tracheobronchial stenosis: long-term follow-up. Eur J Cardiothorac Surg. 2010;38:198-202.

8. Colt HG, Dumon JF. Airway stents. Present and future. Clin Chest Med. 1995;16: 465-78.

9. Kim H. Stenting therapy for stenosing airway disease. Respirology. 1998;3:221-8.

10. Dumon JF. A dedicated tracheobronchial stent. Chest. 1990;97:328-32.

11. Gaissert HA, Grillo HC, Wright CD, Donahue DM, Wain JC, Mathisen DJ. Complication of benign tracheobronchial strictures by self-expanding metal stents. $J$ Thorac Cardiovasc Surg. 2003;126:744-7.

12. Kim HJ, Koh WJ, Suh GY, Chung MP, Kim JG, Suh SW, et al. The usefulness and safety of natural stent in a canine model of tracheal stenosis. Tuberc Respir Dis. 2002;53:431-8.

13. Ryu YJ, Kim H, Yu CM, Choi JC, Kwon YS, Kim J, et al. Comparison of natural and Dumon airway stents for the management of benign tracheobronchial stenoses. Respirology. 2006;11:748-54. 
14. Nam HS, Um SW, Koh WJ, Suh GY, Chung MP, Kwon OJ, et al. Clinical application of the Natural Y stent in the management of benign carinal stenosis. Ann Thorac Surg. 2009;88:432-9.

15. Ryu YJ, Kim H, Yu CM, Choi JC, Kwon YS, Kwon OJ. Use of silicone stents for the management of post-tuberculosis tracheobronchial stenosis. Eur Respir J. 2006;28:1029-35.

16. Park HY, Kim H, Koh WJ, Suh GY, Chung MP, Kwon OJ. Natural stent in the management of post-intubation tracheal stenosis. Respirology. 2009;14:583-8.

17. Vergnon JM, Costes F, Polio JC. Efficacy and tolerance of a new silicone stent for the treatment of benign tracheal stenosis: preliminary results. Chest. 2000;118: $422-6$.
18. Mayse ML, Greenheck J, Friedman M, Kovitz KL. Successful bronchoscopic balloon dilation of nonmalignant tracheobronchial obstruction without fluoroscopy. Chest. 2004;126:634-7.

19. Zias N, Chroneou A, Tabba MK, Gonzalez AV, Gray AW, Lamb CR, et al. Post tracheostomy and post intubation tracheal stenosis: report of 31 cases and review of the literature. BMC Pulm Med. 2008;8:18.

20. Low SY, Hsu A, Eng P. Interventional bronchoscopy for tuberculous tracheobronchial stenosis. Eur Respir J. 2004;24:345-7.

21. Puma F, Ragusa M, Avenia N, Urbani M, Droghetti A, Daddi N, et al. The role of silicone stents in the treatment of cicatricial tracheal stenoses. J Thorac Cardiovasc Surg. 2000;120:1064-9.

Access to The Journal of Thoracic and Cardiovascular Surgery Online is reserved for print subscribers!

Full-text access to The Journal of Thoracic and Cardiovascular Surgery Online is available for all print subscribers. To activate your individual online subscription, please visit The Journal of Thoracic and Cardiovascular Surgery Online, point your browser to http://www.mosby.com/jtcvs, follow the prompts to activate your online access, and follow the instructions. To activate your account, you will need your subscriber account number, which you can find on your mailing label (note: the number of digits in your subscriber account number varies from 6 to 10). See the example below in which the subscriber account number has been circled:

\section{Sample mailing label}

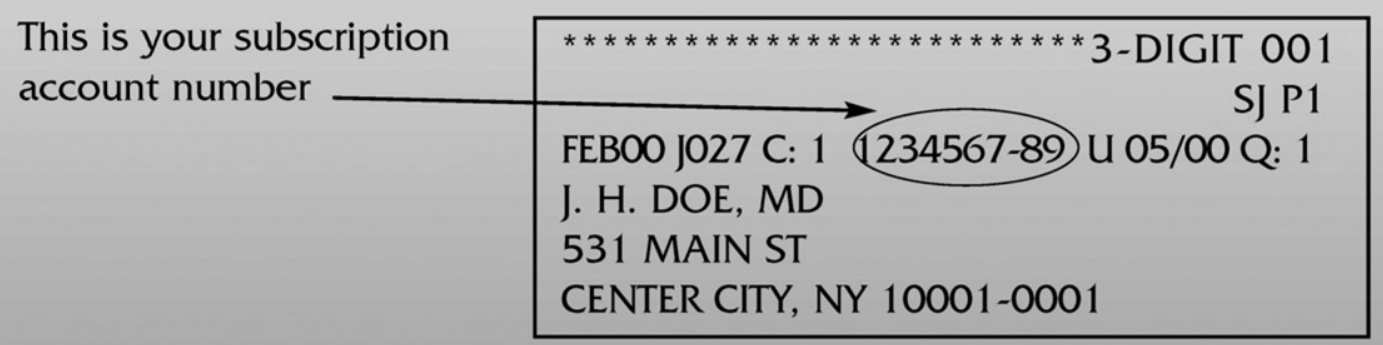

Personal subscriptions to The Journal of Thoracic and Cardiovascular Surgery Online are for individual use only and may not be transferred. Use of The Journal of Thoracic and Cardiovascular Surgery Online is subject to agreement to the terms and conditions as indicated online. 